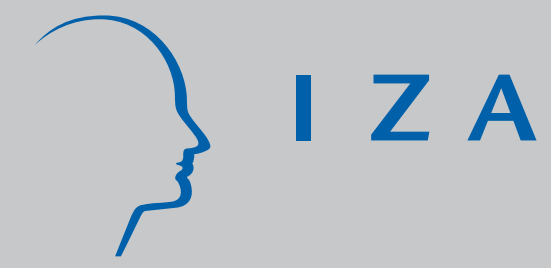

IZA DP No. 7135

Delayed First Birth and New Mothers' Labor Market Outcomes: Evidence from Biological Fertility Shocks

Massimiliano Bratti

Laura Cavalli

January 2013 


\title{
Delayed First Birth and New Mothers' Labor Market Outcomes: Evidence from Biological Fertility Shocks
}

\author{
Massimiliano Bratti \\ Università degli Studi di Milano, \\ CHILD, Ld'A and IZA \\ Laura Cavalli \\ Università degli Studi di Verona \\ and Università Bocconi
}

\section{Discussion Paper No. 7135 \\ January 2013}

IZA

\author{
P.O. Box 7240 \\ 53072 Bonn \\ Germany
}

\author{
Phone: +49-228-3894-0 \\ Fax: +49-228-3894-180 \\ E-mail: iza@iza.org
}

\begin{abstract}
Any opinions expressed here are those of the author(s) and not those of IZA. Research published in this series may include views on policy, but the institute itself takes no institutional policy positions. The IZA research network is committed to the IZA Guiding Principles of Research Integrity.

The Institute for the Study of Labor (IZA) in Bonn is a local and virtual international research center and a place of communication between science, politics and business. IZA is an independent nonprofit organization supported by Deutsche Post Foundation. The center is associated with the University of Bonn and offers a stimulating research environment through its international network, workshops and conferences, data service, project support, research visits and doctoral program. IZA engages in (i) original and internationally competitive research in all fields of labor economics, (ii) development of policy concepts, and (iii) dissemination of research results and concepts to the interested public.
\end{abstract}

IZA Discussion Papers often represent preliminary work and are circulated to encourage discussion. Citation of such a paper should account for its provisional character. A revised version may be available directly from the author. 


\section{ABSTRACT}

\section{Delayed First Birth and New Mothers' Labor Market Outcomes: Evidence from Biological Fertility Shocks *}

We investigate the impact of delaying the first birth on Italian mothers' labor market outcomes around childbirth. The effect of postponing motherhood is identified using biological fertility shocks, namely the occurrence of miscarriages and stillbirths. Focusing on mothers' behavior around first birth our study is able to isolate the effect of motherhood postponement from that of total fertility. Our estimates suggest that delaying the first birth by one year raises the likelihood of participating in the labor market by 1.2 percentage points and weekly working time by about half an hour, while we do not find any evidence that late motherhood prevents a worsening of new mothers' job conditions (the so-called "mommy track"). Our findings are robust to a number of sensitivity checks, among which including controls for partners' characteristics and a proxy for maternal health status.

JEL Classification: J13, J22

Keywords: delayed first birth, fertility shocks, Italy, labor market, new mothers

Corresponding author:

Massimiliano Bratti

DEMM

Università degli Studi di Milano

via Conservatorio 7

20122 Milano

Italy

E-mail: massimiliano.bratti@unimi.it

\footnotetext{
* We gratefully acknowledge Cinzia Castagnaro and Claudia laccarino from ISTAT for providing us with some useful data to integrate the publicly available version of the Italian Birth Sample Survey's first wave. Participants to presentations given at the 7th European Workshop on Labour Markets and Demographic Change (St. Gallen), the University of Milan and the University of Verona are gratefully acknowledged for their comments and suggestions. The usual disclaimers apply.
} 


\section{Introduction}

In the last decades two changes in women's behavior have attracted considerable attention by researchers in various social sciences: the increase in the age at first birth (see, for instance, Happel et al. 1984, Cigno and Ermisch 1989, Chen and Morgan 1991, Blackburn et al. 1993, Gustafsson 2001, Kohler et al. 2002, Frejka and Sardon, 2006), which is generally associated with a reduction in female total fertility, and the rise in labor force participation (see Killingsworth and Heckman 1987, Fernandez et al. 2004, Blau and Kahn 2007, Thevenon 2009, Fogli and Veldkamp 2011, among the others).

The positive association between age at first birth and female attachment to the labor force is not limited to historical time-series data but can also be found in cross-sectional and panel data (Hofferth, 1984, Nicoletti and Tanturri 2008). In the Italian survey used in this paper, for instance, women who gave birth at ages 25-27 have ceteris paribus a probability of participating to the labor market around childbirth (roughly speaking when the child is 18-26 months old, in our analysis) which is 9 percentage points lower than that of women who became mothers at ages 32-34.

Motherhood postponement and female labor market outcomes appear to be closely related, and the idea that delaying first birth may help women to reduce the negative effects of fertility on their labor market perspectives has gained increasing popularity (see the next section). However, association does not necessarily mean causation, and critics of this interpretation maintain that motherhood postponement and better women's labor market outcomes may both be the result of a third unobserved variable, such as a change in values and norms for which it becomes more socially acceptable for women to become mothers at older ages and to devote their energies to their work careers when they are still young (see Liefbroer and Billari, 2010). 
In a cross-sectional setting women's labor market attitudes, which are hard to observe, may affect both their fertility and labor market behavior. Thus women giving birth later may also be those who are more career oriented. Distinguishing between the two hypotheses is difficult and requires finding an exogenous source of variation in the timing of first birth, which must be uncorrelated with women's attitudes towards working in the market.

A potential source of exogenous variation for both motherhood postponement and the number of children may be provided by "infertility shocks", namely the presence of factors limiting a woman's fecundability, or "fertility shocks" such as miscarriages or stillbirths. In the remainder of this paper we will refer to "infertility shocks" as to women's infertility or subfertility conditions decreasing their likelihood of getting pregnant, and to "fertility shocks" as to the situations in which a pregnancy is involuntarily interrupted. Scholars have recently exploited these potential sources of identification to estimate the causal effect of the number of children on female labor force participation and labor supply (see Cristia 2008, Agüero and Marks 2008, 2011, Rondinelli and Zizza 2011, among others).

Yet the use of biological shocks to estimate the effect of motherhood postponement has been much more limited. To the best of our knowledge, this has been done only by Miller (2011), which uses a combination of both "infertility shocks" and "fertility shocks" to estimate the causal effect of the timing of first birth on mothers' earnings, wages and working hours. However, studying the impact of fertility timing on mother's labor market outcomes is at least as important as studying the effect of total fertility. Indeed, higher age at first birth is likely to affect post-birth mothers' labor market behavior and outcomes through the accumulation of pre-birth human capital, which raises the cost of a mother's withdrawing from the labor market after childbirth. 
The present paper seeks to contribute to this newborn and scant literature. Compared to the other only study existing on the topic, we add to Miller (2011) in three main respects. First, we consider other labor market outcomes in addition to female labor force participation and working hours, namely the likelihood of mothers" "upgrading" or "downgrading" of various job characteristics after childbearing (what Miller defines the "mommy track"). ${ }^{1}$ Second, we focus only on behavior around the first birth, so as all mothers in our analysis have the same number of children (i.e., actual fertility), and the effect of motherhood postponement is not confounded with that of realized fertility. This is made possible thanks to the use of a birth survey, in which women experiencing first births are oversampled compared to ordinary cross-sectional or longitudinal surveys. This represents a major difference with respect to Miller (2011), since, as we describe in Section 2, her analysis cannot distinguish between the "pure" effect of timing and the one mediated by the effect of postponement on total fertility (what are generally called “tempo effects"). ${ }^{2}$ Last but not least, we study the effect of fertility timing on mothers' labor market outcomes in a context of very low fertility (Kohler et al. 2002, Kertzer et al. 2009). Italy represents an interesting case study owing to its persisting low levels of fertility and female labor force participation. In spite of the ambitious target which was set by the Lisbon strategy for women's employment (60 percent by 2010), Italy still lags behind with a female employment rate in the age group 15-64 of 46.5 percent in 2011 (source: ISTAT time series on the labor market). Several reasons have been advocated for these low levels of women's labor market attachment, such as the lack of public child-care (Del Boca and Vuri, 2007), a welfare model still

\footnotetext{
${ }^{1}$ As we will say later, wages are not available in our dataset, and for this reason we will not able to estimate the effect of delaying motherhood on wages.

${ }^{2}$ She estimates accordingly the reduced form effect of fertility timing, including the effect on total fertility, and not the "pure" effect of postponing motherhood.
} 
too centered on the role of women as the main care givers for both children and the elderly (Villa and Bettio 1998, Pagani and Marenzi, 2008), or the lack of flexible work arrangements capable of reconciling family and market work such as part-time employment opportunities (Del Boca, 2002). Thus, also from a policy point of view, it is interesting to understand whether "tempo policies" (Lutz and Skirbekk 2005), i.e. policies aimed at affecting the timing of the first birth, could be used by policy makers to increase women's labor force participation and labor supply.

Our paper is also interesting from a methodological point of view, as we address the endogeneity of age at first birth with respect to labor market outcomes by applying a two-step procedure, where the first step is an interval regression. This is due to the nature of our data in which women's age at first birth was released only in grouped form for confidentiality reasons. The methods used in this paper can be applied whenever an endogenous variable is observed in grouped form but the researcher is interested in estimating an outcome equation in which it must enter as a continuous variable.

Using data on a representative sample of births in Italy, our analysis shows that nature provides a good randomization of age at first birth through biological fertility shocks. Indeed, women who were subject to miscarriage or stillbirth do not differ significantly from those who were not subject to these shocks in many observed characteristics potentially related to their labor market behavior. We focus on women who were working when they realized they were pregnant and estimate that delaying motherhood by one year increases new mothers' probability to participate in the labor market around the first birth by about 1.2 percentage points, and weekly working time by about half an hour. Some robustness checks show that our main findings are not sensitive to including in the econometric specifications additional control variables related to women's health and their partners' characteristics. 
We also analyze the changes in working conditions for the women who were working for the same employer before and after childbearing to shed light on possible forms of labor market discrimination and job "downgrading" related to the timing of childbearing, as potentially posited by the "mommy track" described in Miller (2011). However, we do not find any association between late motherhood and job "downgrading" in terms of doing less interesting job tasks, having lower responsibilities, career and training opportunities, or wages, although our analysis is limited to the first two years after childbirth, and such an effect may take place only in the medium or long run.

The structure of the paper is as follows. Section 2 reports a brief survey of the past literature on the labor market returns to delaying childbearing. Section 3 describes the key features of the data we use, and Section 4 our identifying strategy. The main results on the effect of age at first birth on labor force participation and working hours along with some robustness checks are reported in Section 5. Section 6 provides further evidence on job "downgrading" following the first birth. Section 7 summarizes the main findings and concludes.

\section{Theoretical insights and past empirical evidence on the effects of age at first birth on mothers' labor market outcomes,}

The economic literature has already stressed that age at first birth represents a choice variable for women (see Gustafsson, 2001 for a review) and is therefore likely to be endogenous with respect to women's labor market behavior. The focus has been concentrated on explaining the historical trend towards delaying first birth. Two main reasons have been advocated for this phenomenon, the "consumption smoothing" motive and the "career planning" motive. According to the first motive, women tend to postpone childbearing to periods in which they have relatively 
higher earnings to smooth consumption over time. According to the "career planning" motive instead women postpone childbearing to periods when this is less penalizing for their careers, typically to when the age-earning profile is relatively flat.

This literature also offers some theoretical insights into the reasons why postponing motherhood may have a positive effect on female labor force participation. In the model by Happel et al. (1984), for instance, women wish to determine the optimal timing of birth by maximizing life-time earnings. In this model childrearing entails a fixed-duration absence from the labor market (work interruption) during which women's human capital is subject to depreciation. The amount of job experience accumulated before marriage plays a crucial role in determining whether women's skills totally or partly decay during the work interruption. When the rate of human capital depreciation (skill decay) and pre-birth human capital levels are high, women will be relatively more likely to give birth later. The reverse is true, i.e. early childbirth is more frequent, for women with low skill depreciation (e.g., low skilled manual workers) or low pre-marriage human capital. The only case in the model in which earlier childbirth is preferred to late childbearing is indeed when skills are totally lost during a work interruption. Thus for some women late childbearing may be an effective way of increasing labor market earnings. Similar implications can also be found in the model of Erosa et al. (2002) in which early childbearing is costly because it increases the probability of mothers' future job separations.

The empirical labor economics literature has generally found that these theoretical predictions are consistent with the data. The wage differential between mothers and childless women, sometimes defined the "family wage gap" or the "motherhood wage gap", has been studied extensively by both economists and sociologists (see, for instance, Browning 1992, Dankmeyer 1996, Budig and England 2001). The literature focusing on such issue shows a 
positive correlation between age at motherhood and women's wages, suggesting a possible incentive for delaying motherhood of women who plan to spend their adulthood in the labor force. This has been found in several countries. Chandler et al. (1994) find for European countries that a one-year delay in the first birth is associated with 2.1 percent greater wage growth among married women working full-time. Taniguchi (1999) uses the US National Longitudinal Survey young women's cohort and finds that compared to women without kids, those with first births at age 28 or beyond face no wage penalty, and those who gave their first birth between ages 20 and 27 suffer a 4 percent wage penalty. Similarly to Taniguchi (1999), Ammuedo-Dorantes and Kimmel (2005) use the US National Longitudinal Survey of Youth (NLSY) but focus on college educated women, finding that late mothers - those who delay beyond age 30- have a 13 percent wage premium. Wilde et al. (2010) use the same data to focus both on low and on high skilled women and show that delaying motherhood increases wages only for high ability (AFQT) women: 1.1 percent more for each year of delay. Troske and Voicu (2010), studying the simultaneity of fertility and employment decisions, find that for US married women delaying childbirth (i.e., postponing it at least one year after marriage) is associated with higher probabilities of labor force participation and of working full time or part time before the first childbirth, and reduces the negative effect on employment thereafter.

Unobserved heterogeneity is the main econometric issue to be tackled when studying the effect of a delayed first birth on new mothers' labor market outcomes. Indeed, mothers who give birth later may also be those that command higher wages in the labor market and exhibit higher present levels of attachment to the labor force, which may reflect both into higher future wages and future labor supply. Solving this potential problem of endogeneity of delayed first birth with 
women's labor market outcomes requires finding a source of presumably exogenous variation in the timing of first childbirth.

This is certainly a hard task. Among the papers cited above, for instance, Wilde et al. (2010) explicitly recognize that it is difficult to find exogenous sources of variation ("instruments") for fertility timing, and for this reason exploit longitudinal data controlling for fixed effects and examining the changes in wage trajectories as respondents become parents. Ammuedo-Dorantes and Kimmel (2005) use family background characteristics -such as the mother's and the father's highest educational grades completed, and a dummy variable for the respondent's living with her parents by age 18- to identify the motherhood and delayed motherhood effects in the wage regression. Troske and Voicu (2009) use several sources of identification, namely distributional assumptions, non-linearity and the number of a woman's siblings who had children (which is a proxy for "taste for children") as an exclusion restriction. As for the latter, the main idea is that siblings' fertility behavior affects fertility decisions through social interactions occurring in the context of interpersonal networks. ${ }^{3}$

Some of the exclusion restrictions used for identification by the past literature have been criticized since they may have a direct effect on mother's labor market outcomes or be endogenous, in particular those related to family background. To address this criticism, some studies have used fertility and infertility shocks to identify the causal effect of the number of children on women's labor market outcomes (Agüero and Marks 2008, 2011, Cristia 2008). The same source of identification has been recently used by Miller (2011) to identify the causal effect

\footnotetext{
${ }^{3}$ However, one may also think that for the same reasons siblings' behavior directly affects women's labor force participation (e.g., a woman's sisters may have a higher fertility and a lower participation in the labor market, and act as "role models").
} 
of delaying first birth. The idea is that women experiencing these shocks give birth later, but that biological shocks should be random with respect to women's characteristics related to labor force attachment. Miller (2011) uses as sources of exogenous variation in timing at first birth an indicator for first pregnancy ending in miscarriage or stillbirth, an indicator for "accidental" first pregnancy occurring while using contraception and the lag in years from the first attempt to conceive to first birth. Using the NLSY, she finds that motherhood delay leads to a $9 \%$ increase in earnings, a $3 \%$ increase in wages, and a $6 \%$ increase in work hours per year of delay. The effects are not the same for all women, and women with college degrees and those in professional and managerial occupations receive the greatest returns from postponing motherhood. As women that have a later first birth also tend to have lower fertility, in some specifications of the wage equation Miller also controls for the number of children. This variable is likely to be endogenous, and to address this issue she uses the same instruments employed for the timing of first birth. Unfortunately, weak identification leads to insignificant estimates for both age at first birth and the number of children. For this reason, in most of the following specifications she drops the latter variable. Hence, in her study age at first birth is likely to also capture the effect of total fertility. ${ }^{4}$

\footnotetext{
${ }^{4}$ Indeed, some previous studies —using IVs strategies, and mainly twinning or sibling-sex composition as instruments — have found a negative effect of the number of children on mothers' labor market outcomes such as labor force participation, working hours, wages and earnings (see Angrist and Evans 1998; Jacobsen et al. 1999, Cruces and Galiani 2007). However, the findings of papers using fertility or infertility shocks to identify the causal effects of the number of children are "mixed". Rondinelli and Zizza (2010), for instance, expressly focus on Italy and use the fact that women cite biological/physiological factors as a reason for the mismatch between their actual and their desired number of children as instruments in a IVs strategy to identify the causal effect of the number of children on women's labor market attachment. The authors find no effect of the number of children on labor force
} 
Thus compared to Miller (2011), but also to Rondinelli and Zizza (2010) and Agüero and Marks $(2008,2011)$ among the others, our paper is able to disentangle more clearly the direct effect of delaying motherhood from the indirect effect, which is mediated by the number of children.

\section{Data}

The data used in this paper come from the Italian "Birth Sample Survey" (BSS, hereafter), gathered by the Ministry of the Interior and diffused by ISTAT (Italian National Statistical Institute). There are two waves of the BSS, collected at the end of 2003 and at the end of 2005 respectively. ${ }^{5}$

The focus of the BSS is on women who recently experienced childbirth. The sample for the first wave was extracted from Population Registers of the births of 2001 in order to gather information regarding the births occurred between the period July 2000-June 2001; the sample for the second wave was extracted from Population Registers of the births of 2003 (JanuaryDecember 2003); they both represent about 10 per cent of the total births registered in those periods.

The choice of this specific survey has been dictated by the fact that in the collection of the data particular attention has been devoted to the interaction between maternity and female participation in the labor market. Thus the data allow the researcher to track changes in women's

participation, weekly working hours, years of contribution, working time, type of contract, job quality, and potential experience.

${ }^{5}$ The number of births and the information about the mothers are found in the Population Registers, through the P4 Model introduced from ISTAT that releases these data. Both are available at: www.demo-istat.it. The survey structure and main results are described in ISTAT (2006). 
work status and job characteristics after childbearing. Another important aspect of the dataset is that being the focus of BSS only on mothers, it contains a large number of births compared to other cross-sectional or longitudinal data focused on the whole population, and includes data on miscarriages and stillbirths, which are crucial for our identifying strategy. ${ }^{6}$

The pooled sample from the two BSS waves includes 32,459 women who recently experienced childbirth. For the sake of the analysis in this paper we imposed some sample selection criteria. First, as we already argued in the introduction, in order to the disentangle the effect of timing of first birth from the effect of total fertility we focus only on women for which the birth recorded in Population Registers was the first parity ("new mothers") and for which it was not a twin-birth. For the same reason, we drop all women who at the date of the interview had a second child or were pregnant. We further select the women who were participating in the labor market (either employed or unemployed) when they realized they were pregnant. We think that this is the relevant population to estimate the effect of the timing of first birth on female labor force participation, as the case of women starting to participate in the labor market after childbearing is very rare in Italy. To put in other words, women who were not participating in the labor market before childbearing may have made a life-time decision, and for them the timing of first birth is unlikely to affect labor market behavior. We select only women whose age at first birth is lower than 35 . The reason is that after 34 women's age may become an important risk factor for miscarriage and stillbirth (Nybo Andersen et al. 2000, Cleary-Goldman et al. 2005),

\footnotetext{
${ }^{6}$ The BBS only provides information on having experienced miscarriage and stillbirth in the past, while does not gather information on the age at which a woman experienced it. For this reason, we cannot use fertility shocks to instrument postponement of parities higher than the first (e.g., for a woman with two children we do not know if the miscarriage or stillbirth took place before or after the first parity).
} 
and the positive correlation between fertility shocks and age at first birth may be due to reverse causality rather than be a genuine effect of fertility shocks on age at motherhood. ${ }^{7}$ Last but not least, we drop observations with missing values either in the dependent or the independent variables. Table 1 summarizes these sample selection criteria, and the size of the final sample.

It is worth noting that due to the nature of the data collected by the BSS, in this paper we will be able to investigate new mothers' labor market outcomes around the childbirth. After applying the sample selection criteria shown in Table 1, for 99 percent of women the birth recorded in the Population Registers concern children aged between 18 and 26 months at the time of the interview. Is this a relevant time-window (since first birth) for analyzing new mothers' labor market outcomes or do women tend to radically change their behavior when their children become older? Solera (2009) shows that Italian women are unlikely to experience a career break more than once in their lives and that this usually occurs at the time of the birth of the first child. Bratti et al. (2005) analyze the effect of new mothers' characteristics on labor force participation considering different time windows (12, 24 and 36 months since first birth) and show that the estimated effects are largely independent of the specific time window considered. Thus previous research suggests that the time window since first birth spanned by our data gives also useful information on mothers' future labor market behavior. ${ }^{8}$

Sample descriptive statistics are reported in Table 2. In our estimation sample 81.9 percent of women who were participating in the labor market before pregnancy also participate after childbearing. New mothers' average labor supply amounts at 24.2 hours per week.

\footnotetext{
${ }^{7}$ Hence, this last selection criterion is important to ensure that our identification strategy works properly.

${ }^{8}$ This has been found also for other countries, such as the US (Shapiro and Mott, 1994).
} 


\section{Econometric strategy and identification}

In what follows, we describe the main features of our empirical strategy. Let us define first an equation for age at first birth, $a_{i}$, where $i$ is the individual subscript:

$a_{i}=\alpha_{0}+\alpha_{1} S_{i}+\alpha_{2} \mathbf{X}_{\mathbf{i}}+\varepsilon_{i}$,

$S_{i}$ is a measure of exogenous "fertility shocks", $\mathbf{X}_{\mathbf{i}}$ a vector of other exogenous variables, $\varepsilon_{i}$ an error term, and the $\alpha$ 's the parameters to be estimated. As we already said, the public version of the BSS releases the age at first birth only in grouped form, for privacy reasons. We do not observe $a_{i}$ but its grouped counterpart $a_{i}^{*}$, and the observational rule is

$a_{i}^{*}=\left\{\begin{array}{ccc}1 & \text { if } & A_{0} \leq a_{i} \leq A_{1} \\ 2 & \text { if } & A_{1} \leq a_{i} \leq A_{2} \\ \vdots & & \\ n & \text { if } & A_{n-1} \leq a_{i} \leq A_{n}\end{array}\right.$

where the $A_{k}$ 's are the extremes of the age intervals. BSS classifies age at first birth in the following groups: less than $25,25-27,28-29,30-31,32-34,35-36,37-39$ and 40 or more. We consider only relatively younger women, i.e. women falling in the first five age intervals. The reason is that, as we said, after 34 women's age may represent a risk factor for miscarriage and stillbirth, and we want to avoid reverse causality (i.e., women's age may be a cause of miscarriage or stillbirth, see Section 4.1).

The equation for the specific labor market outcome considered $\left(l_{i}\right)$ is

$l_{i}=\beta_{0}+\beta_{1} a_{i}+\beta_{2} \mathbf{X}_{\mathbf{i}}+u_{i}$

where $u_{i}$ is an error term, and the $\beta$ 's are the coefficients to be estimated, among which we are especially interested in $\beta_{1}$ : the causal effect of age at first birth on the labor market outcome considered. Should age at first birth be observed in continuous form, a way of consistently estimating $\beta_{1}$ would be to estimate the first stage equation (1) with ordinary least squares, obtain a prediction for $a_{i}$ and replace it to $a_{i}$ in equation (2) and then estimate it, that is using two-stage 
least squares (2SLS) where $S_{i}$ (fertility shocks) would be the excluded instrument. However, as age at first birth is only observed in grouped form, we need to obtain first a consistent prediction of $a_{i}$ in continuous form in order to apply this procedure. This can be done by assuming an identically normally distributed $\varepsilon_{i}$ with zero mean and variance $\sigma^{2}$ and estimating in the first stage an interval regression with Maximum Likelihood (Stewart, 1983). Indeed, after estimating the interval regression, a consistent prediction for $a_{i}$ is given by

$\hat{a}_{i} \equiv E\left(a_{i} \mid A_{k-1}<a_{i} \leq A_{k}, \mathbf{X}_{\mathbf{i}}\right)=\alpha_{0}+\alpha_{1} S_{i}+\alpha_{2} \mathbf{X}_{\mathbf{i}}+\sigma\left[\frac{f\left(\boldsymbol{Z}_{\boldsymbol{k}-\mathbf{1}}\right)-f\left(\boldsymbol{Z}_{\boldsymbol{k}}\right)}{F\left(\boldsymbol{Z}_{\boldsymbol{k}}\right)-F\left(\boldsymbol{Z}_{\boldsymbol{k}-\mathbf{1}}\right)}\right]$

where $\boldsymbol{Z}_{\boldsymbol{k}}=\left(A_{k}-\alpha_{0}-\alpha_{1} S_{i}-\alpha_{2} \mathbf{X}_{\mathbf{i}}\right) / \sigma$ and $f$ and $F$ are the normal density function and the cumulative normal distribution respectively, and the term in square brackets is the inverse Mill's ratio in case of interval data.

After replacing $\hat{a}_{i}$ in equation (1) we can consistently estimate $\beta_{1}$. The standard errors in the second stage are corrected following the procedure proposed by Murphy and Topel (1985) to take into account the fact that $\hat{a}_{i}$ is a generated regressor. ${ }^{9}$ The model is formally identified by the non linearity of $\hat{a}_{i}$ in the covariates, and exclusion restrictions are not necessary for identification. However, $S_{i}$ is included in the first step to also ensure the "economic" identification of the model and not to rely exclusively on a functional form assumption. ${ }^{10}$

\footnotetext{
${ }^{9}$ This correction can be implemented in Stata as described in Hole (2006).

${ }^{10}$ A normality assumption is used in the first step to estimate the interval regression. Stewart (1983) investigates the consequences of asymmetry in the error distribution, namely the case of log-normal and $\chi^{2}$ distributions, and in both cases report evidence of zero bias when using ML estimation. Only the estimates of the error's variance appear to be biased owing to asymmetry. Bettin and Lucchetti (2012) analyze the impact of leptokurtosis and report a very small bias using ML methods. Thus, ML estimates seem to be fairly robust to deviations from the normality assumption.
} 
From equation (3), it is also important to note that fertility shocks enter the fertility timing process $\left(E\left(a_{i} \mid A_{k-1}<a_{i} \leq A_{k}, \mathbf{X}_{\mathbf{i}}\right)\right)$ in a non-linear fashion through the inverse Mill's ratio. This means that fetal loss is allowed to have a differential effect on fertility timing at different ageintervals. $^{11}$

\subsection{Exogeneity of fertility shocks}

We use miscarriages and stillbirths as exogenous sources of variation in a woman's age at first birth. Miscarriage or spontaneous abortion refers to any pregnancy loss that takes place before the 20th week of pregnancy. A stillbirth is defined as the death of a fetus at any time after the 20th week. Stillbirth is also referred to as intrauterine fetal death (IUFD). Both events produce a postponement of first births, which is relatively longer for stillbirths. A crucial assumption for our identifying strategy to work is that the fertility shocks that we consider are randomly distributed with respect to women's aptitudes towards working after giving birth, i.e. that they are exogenous.

Let us now consider then the main reasons for miscarriages and stillbirths. Only two etiological factors for miscarriage are recognized by different authors in the obstetric literature: uterine malformations and the presence of balanced chromosomal rearrangements in parents (Plouffe et al., 1992). The comprehensive review by García-Enguídanos et al. (2001) cites among the principal behavioral risk factors for miscarriage the use of tobacco and alcohol, ${ }^{12}$ drug

\footnotetext{
${ }^{11}$ This is not the case in "traditional" 2SLS unless higher order terms in $\hat{a}_{i}$ are included in the second stage, which would require additional instruments.

${ }^{12}$ For which the association with miscarriage especially at low levels of consumption of these substances is however unclear
} 
consumption, and previous induced abortion or miscarriage. Recent research from the US shows that although some women's observable characteristics turn out to be associated with the risk of stillbirth, they usually account for a small amount of the variance in this outcome (The Stillbirth Collaborative Research Network Writing Group, 2011a), and in particular obstetric conditions and placental abnormalities are the most common causes of stillbirth (The Stillbirth Collaborative Research Network Writing Group, 2011b). The risk of placental abnormalities however increases significantly after age 35 (Hook, 1981, Nybo-Andersen et al 2005), and to avoid reverse causality (from age at first birth towards miscarriage o stillbirth) our analysis only considers women younger than 35 . From previous research, women's miscarriages and stillbirths do not seem overall to be mainly associated to aspects related to their taste for market work, or work-related factors. ${ }^{13}$

A common way of checking the quality of the randomization provided by fertility shocks is to compare means of observed characteristics of women who were subject to these shocks and women who were not. The idea is that if fertility shocks are truly random, these two groups of women should not differ in their observable characteristics, and hopefully also in their unobserved characteristics which are potentially related to the labor market behavior and

\footnotetext{
${ }^{13}$ When the cause of miscarriages and stillbirths are chromosomal abnormalities, and not women's health conditions, future fertility is not reduced, and especially in case of very early miscarriages the fertility postponement is unlikely to be substantial, as a couple may re-plan a new pregnancy quite soon (ovulation typically restarts by 4-6 weeks since the loss of the fetus). By way of contrast, late miscarriages and especially stillbirths may imply for the couple a longer postponing of the planning of a new pregnancy, and therefore a longer delaying of first birth. Unfortunately the survey we use did not collect separate information for miscarriages and stillbirths, but only provides an aggregate variable. This implies that the effect that we estimate in the first stage (the fertility timing equation) will be the average effect of miscarriages and stillbirths on age at first birth.
} 
outcomes. Table 3 shows the difference in means in women's observed characteristics, along with the corresponding standard errors. Interestingly enough, in all cases the two groups are not statistically different. The smallest $p$-value among all differences in means is 0.146 . Women experiencing fertility shocks are not more educated, do not have a higher desired fertility, more educated partners or partners with different job characteristics.

The randomization that nature provides through fertility shocks seems to be particularly appropriate in our setting, especially compared to previous studies that used infertility or subfertility shocks for identification. In the latter case, indeed, researchers have often reported statistically significant differences between women who were subject and women who were not subject to this type of shocks, finding that the last category of women tend to be more educated, to have more educated partners (Agüero and Marks, 2008, 2011) and to have more educated mothers (Rondinelli and Zizza, 2010).

Unfortunately, the BBS does not collect information on women's health status or healthrelated behaviors, which may affect both fertility timing and mother's labor market outcomes. In this respect, the sample selection criteria we follow turn to our advantage as most women with serious health problems or "extreme" health behaviors (e.g., abusing tobacco or alcohol) are less likely to have participated in the labor market before childbirth, and therefore more likely to be excluded from our estimation sample. Moreover, we are controlling for maternal education, which is strongly correlated with both maternal health and health-related behaviors, such as smoking (Currie and Moretti 2003, de Walque 2007).

However, the unavailability of maternal health status and health related behaviors could still produce an omitted variables bias. For this reason in Section 5 we will investigate the sensitivity or our results to including a proxy for these unobserved characteristics. 
It has to be kept in mind though that our information on fetal losses comes from survey data, i.e. our exclusion restriction is reported miscarriages or stillbirths. ISTAT reports the incidence of miscarriages and stillbirth to be 12.81 for 100 live births in clinical data (ISTAT, 2005, time series). The average incidence of fetal loss computed in the BSS 2002 and 2005 pooled waves (using weights) is 12.66 for 100 live births. Hence in the BSS survey fetal loss does not seem to suffer from substantial under-reporting. ${ }^{14}$

\section{Main results}

The left part of Table 4 reports the estimates of the "first step" regression": the interval regression for age at first birth. In the interval regression we have only included variables which are likely to be predetermined with respect to childbirth: a woman's level of education, geographic area of residence, the number of desired children, a dummy indicator for the BSS wave and our excluded instrument. Among the regressors, it is possible to note the strong positive association between the number of miscarriages and stillbirths and the age at first birth.

\footnotetext{
${ }^{14}$ Wilde et al. (2010) review the main criticism towards using fetal loss as an instrument, although they clearly acknowledge that it is probably the "most clever and compelling instrument" (p.13) used in the literature. Its main weaknesses according to the authors are due to potential under-reporting of miscarriage and stillbirth, and to differences in predetermined characteristics between women who experienced it and women who did not. However, in our case this criticism does not seem to apply (see also Table 3). Another potential criticism is that women who experienced a fertility shock may have worse health, affecting their labor market outcomes. We will provide evidence on this issue in Section 5.1. Last but not least, the authors state that miscarriage and stillbirth is likely to cause only a limited increase in women's age at first birth (a maximum of 2 years in their data). However, this is likely to be true for many instrumental variables estimates using quasi-experiments provided in the literature, for instance those using institutional changes such as increasing in compulsory schooling laws, length of maternal leave, etc.
} 
The Wald test for the exclusion of the fertility shocks from the first stage returns a $\chi^{2}(1)$ of 53.82 confirming the strength of our excluded instrument. When the coefficient is translated in marginal effect, increasing by one the number of fertility shocks raises the likelihood of giving birth between the ages 30 and 34 by about 6 percentage points. ${ }^{15}$ As expected, age at first birth tends to increase with a woman's education and to decrease with her number of desired children. Women residing in Southern Italy and in the Islands give birth earlier.

The right part of Table 4 reports results for the second stages concerning the probability of female labor force participation (LFP) - estimated with a linear probability model (LPM)- and working hours. ${ }^{16}$ Standard errors are corrected following the procedure suggested in Murphy and Topel (1985). The second stage includes all the controls of the first stage and the age of the child in months. Indeed, women's labor force participation is strongly affected by their generic human capital investments (Bratti, 2003), by their region of residence, by their fertility preferences (see Becker, 1981) and the child's age (as younger children are likely to be more time-intensive).

Delaying first birth by one year raises the likelihood of participating in the labor market by 1.2 percentage points. The coefficient is significant at the $1 \%$ statistical level. ${ }^{17}$ The third column reports the effect on the number of weekly working hours obtained using a linear model. ${ }^{18}$ Also in this case the age at first birth has a significant positive effect, with an increase of 0.54 weekly working hours for a one-year increase in age at motherhood. At the sample mean

\footnotetext{
${ }^{15}$ Marginal effects are not reported in the Table.

${ }^{16}$ See Angrist (2001) for the use of linear models in the presence of dichotomous dependent variables.

${ }^{17}$ We used for LFP a linear probability model, which is robust to non-normality. However, the estimated effect is not very sensitive to changing the functional form. Using a probit model, for instance, the marginal effect of age at first birth is 0.11 .

${ }^{18}$ A linear model and OLS were used for working hours following Miller (2011).
} 
of working hours for working mothers (29.6) 0.54 weekly hours correspond to a 1.8 percent increase in working hours, lower than the estimate of the effect provided by Miller (2011) which finds a 6 percent increase in working hours for a one-year delay in age at first motherhood. However, as we already stressed, Miller's analysis is not limited to women who currently have only one child, and her estimates are likely to combine the effects of both fertility timing and total fertility on labor market outcomes (the "gross effect" of motherhood postponement), and hence to be larger.

Another factor which is positively associated with both women's labor force participation and working hours is education. Women with ISCED 0-2 are 10.3 p.p. less likely to participate in the labor market and offer -3.44 less hours in the labor market than the reference group (ISCED 3-4). ${ }^{19}$ By contrast, women with tertiary education have a 6 p.p. higher probability of participation and provide about two more hours of work per week in the labor market. Participation and labor supply tend to decline proceeding from the North to the South of the country. Women from the South, for instance, are 6.4 p.p. less likely to participate than women from Center Italy, and supply 4.3 less weekly hours. Another factor which is significantly associated with both LFP and working hours is immigrant status: foreign mothers tend to have significantly lower participation and labor supply.

\footnotetext{
${ }^{19}$ ISCED stands for International Standard Classification of Education. ISCED 1: early childhood education; ISCED 2: primary schooling; ISCED 3: lower secondary schooling; ISCED 4: upper secondary schooling; ISCED 5: undergraduate degree; ISCED 6: postgraduate degree.
} 


\subsection{Robustness checks}

As we have already observed, the BSS does not gather information neither on women's health status nor on health-related behavior, such as alcohol or tobacco consumption, and we cannot control for these factors which could potentially affect a woman's likelihood of experiencing a late childbirth and her labor market outcomes. The nature of the data and the sample selection we made, focusing on women who were working when they discovered they were pregnant, contribute to partially addressing these issues. Indeed (i) the survey collects information on mothers, that is women who managed to get pregnant and to successfully give birth, which are unlikely then to be severely ill or abusing alcohol or tobacco; on top of that, (ii) we consider women who were participating in the labor market before childbirth, which again are unlikely to be those with very poor health status or abusing health-damaging substances.

However, as a further check we include among the control variables a proxy for a woman's health status and health-related behavior: child low birth weight. It is well known from the medical literature that smoking is associated with a higher probability of child low birth weight (see, for instance, Abel et al. 1980, Lumley et al. 1987, Li Qing et al. 1993, Walsh 1994, Perkins et al. 1997). Evidence on the relationship between drinking alcohol during pregnancy and low birth weight is more "mixed". While alcohol abuse increases the likelihood of pre-term birth, the evidence seems to suggest that a low consumption may have a protective effect (Abel et al. 1995, Kesmodel et al. 2000). Low child birth weight is also associated with some chronic medical conditions such as hypertension and diabetes (Bernstein et al 1997). On this ground, we report in Table 5 the estimates of the model including also a dummy indicator for a child's low birth weight (less than 2500 grams). For two observations childbirth weight is missing, and we 
include a missing value indicator to keep the same estimation sample as in Table 4 . Table 5 shows that including a proxy for women's health and health related behavior change neither qualitatively nor quantitatively our conclusions on the effect of motherhood postponement. Moreover, a child's low birth weight is negatively associated only to mother's working time but not to her likelihood of participating in the labor market.

A potential criticism with our baseline specification is that it does not include partner's characteristics, which may affect age at first birth and the mother's labor market outcomes. Indeed, the "consumption smoothing motive" for postponing motherhood (Gustafsson, 2001) posits that women will have children when their household incomes are high enough to bear the additional child-rearing costs, and to smooth consumption overtime. Partner's characteristics may have a direct effect on female labor force participation (income effect). Hence, it may be important to include proxies for household income (partner's characteristics) in the estimated equations as this helps address any potential residual endogeneity generated by omitted variables. In the presence of such residual endogeneity, we might expect the coefficient on age at first birth to be affected by the inclusion of such additional controls. Moreover, another possible source of concern is that richer households may afford better medical services and lower the risk of miscarriage and stillbirth. For these reasons we checked the sensitivity of our estimates to including the characteristics of women's partners. In particular, we included among the covariates the partner's educational level, job qualification (self-employed, white-collar worker, blue-collar worker), sector of activity (public sector vs. private sector) and age (a dummy for partner older than 35), which is also a proxy of labor market experience. ${ }^{20}$ All these factors are also proxies of partner's income, which is not available in the survey. The results are reported in

\footnotetext{
${ }^{20}$ The characteristics included are those of the current husband or partner.
} 
Table 5, and show that the estimated effects of age at first birth on LFP and working hours are very close to (sometimes the same as) those shown in Table 4. This is what one would expect given that our identification is based on biological fertility shocks, which as reported in Table 3 appear to be exogenous, and orthogonal to several women's and partners' observed characteristics.

There may be heterogeneous effects of age at first birth according to a mother's skill level. Indeed, Miller (2011) found the effect of postponing motherhood on wages to be higher for college graduates, and for mothers in professional or managerial occupations. To shed light on potential heterogeneous effects we estimated a specification including interactions terms between $\hat{a}$ and two dummies for mother's ISCED 0-2 and ISCED 5-6, respectively. In the regression for LFP, we obtain a significant coefficient on $\hat{a}$ of 0.0136 (s.e.=0.0018), while only the interaction between $\hat{a}$ and ISCED 5-6 turns out to be statistically significant and negative, -0.011 (s.e.=0.0037). ${ }^{21}$ Hence, the positive effect of age at first birth on mother's LFP appears to be higher for low educated women by 1.1 percent points (p.p. hereafter). This evidence can be rationalized on the grounds that university educated women tend to be more attached to the labor market irrespective of the timing of first birth. Indeed, the amount of working experience that they lose by giving birth early is more than compensated by the general human capital acquired through education (see Section 2). By way of contrast, the human capital that low educated women "gain" in the labor market by postponing motherhood may turns out to be crucial to prevent them from withdrawing from the labor market, as it may make them more desirable to prospective employers. The same specification was also estimated for weekly working hours. In this case the non-interacted coefficient on age at first birth turns out to be 0.537 (s.e=0.0746)

\footnotetext{
${ }^{21}$ These additional results are available from the authors upon request.
} 
very close to that obtained in the non-interacted specification, but none of the interaction terms is statistically significant.

\section{Further evidence}

Miller (2011) observes how new mothers tend to experience a "mommy track" characterized by reduced earnings around the time of first birth, together with a flattening of their wage profile following motherhood. Although her data do not allow determining the precise causal pathways of this effect, she puts forward that "on the supply side, mothers may reduce their hours in the labor market and invest less in skill development. From the demand side, employers may offer to mothers fewer training and advancement opportunities" (p.1097). Evidence on the first effect has been provided in Section 5, in which we have shown that late motherhood has a positive effect on weekly working hours. We try here to exploit information provided by BSS to shed further light on this issue by investigating the changes in job characteristics experienced after first birth by mothers who are employed in the same jobs as before birth. BSS asks mothers specific questions on changes of task, responsibilities, career opportunities, changes in training, wage, "job attachment" and having received pressures related to childbirth from colleagues or the employer. For all these aspects, except for the last one which is a dichotomous variable (yes/no), the possible answers are: no change, better opportunities, or worse opportunities. All these questions are asked to women who were working for the same employer after childbirth. The answers are not mutually exclusive and a woman can cite a worsening of several aspects of her job. We built dichotomous variables for having experienced a worsening in specific job characteristics after childbearing. Table 6 reports the estimates of LPMs using two-step estimation, each row corresponding to separate regressions using different dependent variables. 
The regressions are estimated on individuals who work for the same employer before and after birth, ${ }^{22}$ and the number of observations differs by row as we dropped from the sample individuals who did not answer to the question (varying from zero to three observations by question). The results in Table 6 show that there is no evidence of a "protective" effect of age at first birth in terms of avoiding factors which may generate a "mommy track". Indeed, late mothers are not more likely to avoid a worsening of job tasks, job responsibilities, career or training opportunities, wages, to feel lower "job-attachment" or to suffer less fertility-related pressures from colleagues and the employer.

However, we have to keep in mind that two years after the first birth may perhaps be too short a period for the negative effects of childbearing to materialize, and, second, there may be selection effects. Women suffering significant job discrimination may for instance be more likely either to withdraw from the labor market or to change employer. To investigate this last effect, the last row of Table 6 reports the estimate of a LPM for the probability of working for the same employer after childbearing. Among the 6,482 women who were participating in the labor market after childbearing, 74.16 percent work for the same employer. Interestingly enough, in this case we do find a positive effect of late childbearing on the likelihood of working for the same employer: rising age at first birth by one year is associated to an increase in 2.2 p.p. in the

\footnotetext{
${ }^{22}$ Thus there is a multiple sample selection in this case, the first is on working as an employee after childbearing and the second is on being employed for the same employer. As we do not have good exclusion restrictions to address these forms of sample selection, we present in the text only the estimates conditional on working for the same employer. In our estimation sample $81.9 \%$ of women who were working when they realized they were pregnant work after childbearing. On the grounds that women who are more subject to job downgrading are more likely not to participate in the labor force after childbearing or to change employer, the estimates we present in the text may represent lower bound estimates for the risk of a job downgrade.
} 
probability to work for the same employer before and after childbirth. This effect is very precisely estimated.

\section{Concluding remarks}

In this paper we exploit the randomization in women's age at first birth provided by nature through biological fertility shocks (i.e., miscarriages and stillbirths) to investigate the effect of the age at first childbirth on mothers' labor market outcomes. First, we provide evidence that biological fertility shocks look "as good as random", in particular that women who experience miscarriages or stillbirths do not differ from those who did not experience these shocks with respect to observable characteristics (such as education or desired fertility) which are presumably associated with labor market behavior. We then analyze the effect of age at first birth on several labor market outcomes such as labor force participation, working hours, and job "downgrading" following childbirth. We find that delaying the first birth by one year raises the likelihood of participating in the labor market by 1.2 percentage points and weekly working time by about half an hour. Our estimates are robust to a number of sensitivity checks, among which including controls for partners' characteristics and a proxy for maternal health status.

We also investigate the "upgrading" or "downgrading" of job characteristics for mothers who are working for the same employer before and after giving birth and show no evidence that late motherhood help mothers to avoid a worsening in these characteristics around childbirth. Thus, our data do not provide evidence in support of late motherhood preventing a "mommy track", e.g., lower human capital investments by the employer on new mothers. However, these negative effects may not materialize especially around childbirth but later on, and our data is not suitable to investigate these long-term effects. 
A potential policy implication of our study is that "tempo policies", that is policies affecting age at first birth, may also have an impact on female labor force participation and labor supply. Postponing motherhood may represent for women a good strategy to increase the amount of pre-birth human capital and their current wages, all factors which will affect women's postbirth decisions and reduce their likelihood of withdrawing from the labor market following childbirth. A possible concern with these policies is that postponing first motherhood may contribute to reducing total fertility, but recent studies show that this is not the case when governments provide effective instruments to reconcile family and work (family-friendly policies), such as publicly-provided child care or flexible working times (Bratti and Tatsiramos, 2012). Thus, tempo policies may represent an effective means to help Italy and other Southern European countries, where female labor force participation is still very low, to hit the very ambitious target of a 75\% (total) employment rate in the 20-64 age group set by the Europe 2020 strategy.

Our study shares some of the limitations of the existing work investigating the effect of fertility on female labor market outcomes. Like Cristia (2008), for instance, we focus our analysis on first births and, due to the nature of our data, we are able to study the labor market effects only around the birth event. The focus on the first birth only is justified in our study by our aim to separately identify the effect of fertility timing independently of the effect of total fertility, and by the unavailability of credible instruments to also identify the effect of total fertility over and above that of the timing of the first birth. However, in further work it would be interesting (i) to investigate the effects of delaying higher parities on women's labor market outcomes, were information on the exact timing of fertility shocks or other suitable instrumental 
variables available, and (ii) to use longitudinal data to study the long-term consequences of delaying motherhood, and not only the effects observed around childbirth. 


\section{References}

Abel, E.L. (1980). Smoking during pregnancy: A review of effects on growth and development of offspring. Human Biology, 52(4), 593-625.

Agüero, J.M., \& Marks, M.S. (2008). Motherhood and female labor force participation: Evidence from infertility shocks. American Economic Review, 98(2), 500-504.

Agüero, J.M., \& Marks, M.S. (2011). Motherhood and female labor supply in the developing world. Evidence from infertility shocks. Journal of Human Resources, 46(4), 800826.

Amuedo-Dorantes, C., \& Kimmel, J. (2005). The motherhood wage gap for women in the United States: The importance of college and fertility delay. Review of Economics of the Household, 3(1), 17-48.

Angrist, J. (2001). Estimation of a limited dependent variable models with dummy endogenous regressors: Simple strategies for empirical practice. Journal of Business and Economic Statistics, 19(1), 2-16.

Angrist, J.D., \& Evans, W.N. (1998). Children and Their Parents' Labor Supply: Evidence from Exogenous Variation in Family Size. American Economic Review, 88(3), 450477.

Becker G.S. (1981). A treatise on the family. Cambridge, MA: Harvard University Press.

Bernstein, P.S., \& Divon, M.Y. (1997). Etiologies of fetal growth restriction. Clinical Obstetrics and Gynecology, 40(4), 723-729.

Bettin, G., \& Lucchetti, R. (2012). Interval regression models with endogenous explanatory variables, Empirical Economics, 43(2), 475-498.

Blackburn, M.L., Bloom, D.E., \& Neumark, D. (1993). Fertility timing, wages and human capital. Journal of Population Economics, 6(1), 1-30.

Blau, Francine D., \& Lawrence M. Kahn, (2007). Changes in the labor supply behavior of married women: 1980-2000. Journal of Labor Economics, 25, 393-438.

Bratti, M., Del Bono, E., \& Vuri, D. (2005). New mothers' labour force participation in Italy: The Role of Job Characteristics. Labour, 19(s1), 79-121.

Bratti M. (2003). Labour force participation and marital fertility of Italian women: the role of education. Journal of Population Economics 16(3), 525-554.

Bratti, M., \& Tatsiramos, K. (2011). The effect of delaying motherhood on the second childbirth in Europe. Journal of Population Economics, 25(1), 291-321.

Browning, M. (1992). Children and household economic behavior. Journal of Economic Literature, 30(3), 1434-1475.

Budig, M., \& England, P. (2001). The wage penalty for motherhood. American Sociological Review, 66(2), 204-225.

Chandler, T.D., Yoshinori K., \& Werbel, J.D. (1994). Do delays in marriage and childbirth affect earnings? Social Science Quarterly, 75(4), 838-853.

Chen, R., \& Philip Morgan, S. (1991). Recent trends in the timing of first births in the United States. Demography 28(4), 513-533.

Cigno, A. \& Ermisch, J. (1989). A microeconomic analysis of the timing of births. European Economic Review, 33(4), 737-760.

Cleary-Goldman, J., Malone, F.D., Vidaver, J., et al. (2005). Impact of maternal age on obstetric outcome. Obstetrics and Gynecology 105(5), 983-990. 
Cristia, J. (2008). The effect of a first child on female labor supply: Evidence from women seeking fertility services. Journal of Human Resources, 43(3), 487-510.

Cruces, G., \& Galiani, S. (2007). Fertility and female labor supply in Latin America: New causal evidence. Labour Economics, 14(3), 565-573.

Currie, J., \& Moretti, E. (2003). Mother's education and the intergenerational transmission of human capital: Evidence from college openings. The Quarterly Journal of Economics, 118(4), 1495-1532.

Dankmeyer, B. (1996). Long run opportunity-costs of children according to education of the mother in the Netherlands. Journal of Population Economics, (9), 349-361.

de Walque, D. (2007). Does education affect smoking behaviors? Evidence using the Vietnam draft as an instrument for college education. Journal of Health Economics 26(5), 877895.

Del Boca, D. (2002). The effect of child care and part time opportunities on participation and fertility decisions in Italy. Journal of Population Economics, 15(3), 549-573.

Del Boca, D., \& Vuri, D. (2007). The mismatch between employment and child care in Italy: The impact of rationing. Journal of Population Economics, 20(4), 805-832.

Erosa, A., Fuster L., \& Restuccia, D. (2002). Fertility decisions and gender differences in labor turnover, employment, and wages. Review of Economic Dynamics, 5(4), 856-891.

Fernandez, R., Fogli, A., \& Olivetti, C. (2004). Mothers and sons: Preference formation and female labor force dynamics. The Quarterly Journal of Economics, 119(4), 1249-1299.

Fogli, A. \& Veldkamp, L. (2011). Nature or nurture? Learning and the geography of female labor force participation. Econometrica, 79(4), 1103-1138.

Frejka, T., \& Sardon, J. (2006). First birth trends in developed countries: Persisting parenthood postponement. Demographic Research, 15(6), 147-180.

García-Enguídanos, A., Calle, M.E., Valero, J., Luna, S., \& Domínguez-Rojas, V. (2002). Risk factors in miscarriage: A review. European Journal of Obstetrics \& Gynecology and Reproductive Biology, 102(2), 111-119.

Gustafsson, S. (2001). Optimal age at motherhood. Theoretical and empirical considerations on postponement of maternity in Europe. Journal of Population Economics, 14(2), 225-247.

Happel, S.K., Hill, J.K., \& Low, S.A. (1984). An economic analysis of the timing of childbirth. Population Studies, 38(2), 299-311.

Hole, A. R. (2006). Calculating Murphy-Topel variance estimates in Stata: A simplified procedure. The Stata Journal, 6(4), 521-529.

Hook, E.B. (1981) Rates of chromosome abnormalities at different maternal ages. Obstetrics and Gynecology 58(3), 282-285.

Hofferth S.L. (1984). Long-term economic consequences for women of delayed childbearing and reduced family size. Demography, 21(2),141-155.

Kertzer, D. I., White, M. J., Bernardi, L., Gabrielli, G. (2009). Italy's path to very low fertility: The adequacy of economic and second demographic transition theories. European Journal of Population, 25(1), 89-115.

Kesmodel, U., Olsen, S.F., Secher, N.J. (2000). Does alcohol increase the risk of preterm delivery? Epidemiology, 11(5), 512-518.

Kohler, H.-P., Billari, F.C., Ortega, J.A. (2002). The emergence of lowest-low fertility in Europe during the 1990s. Population and development review, 28(4), 641-680. 
Killingsworth, M.R. \& Heckman, J.J. (1987). Female labor supply: A survey. In: O. Ashenfelter \& R. Layard (Ed.), Handbook of Labor Economics, edition 1, volume 1, chapter 2, pp.103-204. Amsterdam: Elsevier.

Jacobsen, J., P., Pearce, J.W., \& Rosenbloom, J. L. (1999). The effects of childbearing on married women's labor supply and earnings: Using twin Births as a natural experiment. Journal of Human Resources, 34(3), 449-474.

ISTAT, Istituto Nazionale di Statistica, (2006). Forze di Lavoro 2004, Roma: Annuario 10, Serie Lavoro.

Li, C.Q., Windsor, R., Perkins, L., Goldenberg, R.L., \& Lowe, J. B. (1993). The Impact on infant birth weight and gestational age of cotinine-validated smoking reduction during pregnancy. JAMA,269(12),1519-1524.

Liefbroer, A.C., \& Billari, F.C. (2010). Bringing norms back in: A theoretical and empirical discussion of their importance for understanding demographic behavior. Population, Space and Place, 16(4), 287-305.

Lumley J. (1987). Stopping smoking. BJOG, 94(4), 289-292.

Lutz, W., \& Skirbekk, V., (2005). Policies addressing the tempo effect in low-fertility countries. Population and Development Review, 31(4), 699-720.

Miller, A.R. (2011). The effects of motherhood timing on career path. Journal of Population Economics, 24(3), 1071-1100.

Murphy, K.M., \& Topel, R.H. (1985). Estimation and inference in two-step econometric models. Journal of Business \& Economic Statistics, 3(4), 370-379.

Nicoletti C., \& Tanturri M.L. (2008). Differences in delaying motherhood across European countries: Empirical evidence from the ECHP, European Journal of Population, 24(2), $157-183$.

Nybo A., Wohlfahrt, J., Christens, P., Olsen, J., \& Melbye, M. (2000). Maternal age and fetal loss: Population based register linkage study. BMJ, 320(7283), 1708-1712.

Pagani, L. \& Marenzi, A. (2008). The Labor Market Participation of Sandwich Generation Italian Women. Journal of Family and Economic Issues, 29(3), 427-444.

Perkins, S.L., Belcher, J.M., \& Livesey, J.F. (1997). A Canadian tertiary care centre study of maternal and umbilical cord cotinine levels as markers of smoking during pregnancy: relationship to neonatal effects. Canadian Journal of Public Health, 88(4), 232-237.

Plouffe Jr. L, White, E.W., \& Tho, S.P., et al. (1992). Etiologic factors of recurrent abortion and subsequent reproductive performance of couples: have we made any progress in the past 10 years? American Journal of Obstetrics \& Gynecology, 167(2), 313-321.

Rondinelli, C., \& Zizza, R. (2010). (Non)persistent effects of fertility on female labour supply. Tema di discussione Banca D'Italia, 783. Roma: Banca d'Italia.

Solera, C. (2009). Women in and out of paid work. Changes across generations in Italy and Britain. Bristol: The Policy Press.

Shapiro, D., \& Mott, F. (1994). Long-term Employment and Earnings of Women in Relation to Employment Behavior Surrounding the First Birth, Journal of Human Resources, 29(2), 248-275.

Stewart, M.B. (1983). On least squares estimation when the dependent variable is grouped. Review of Economic Studies, 50(4), 737-753.

Taniguchi, H. (1999). The timing of childbearing and women's wages. Journal of Marriage and the Family, 61(4), 1008-1019. 
The Stillbirth Collaborative Research Network Writing Group (2011a). Association between stillbirth and risk factors known at pregnancy confirmation, JAMA, 306(22), 24692479.

The Stillbirth Collaborative Research Network Writing Group (2011b). Causes of death among stillbirths, JAMA, 306(22), 2459-2468.

Thevenon, O. (2009). Increased women's labour force participation in Europe: Progress in the work-life balance or polarization of behaviours? Population 64(2), 235-272.

Troske, K.R., \& Voicu, A. (2009). The effect of the timing and spacing of births on the level of labor market involvement of married women. IZA Discussion Paper, 4417. Bonn: IZA.

Van Noord-Zaadstra, B.M., Looman, C.W., Alsbach, H., Habbema, J. D., te Velde, E. R., \& Karbaat, J., (1991). Delaying childbearing: Effect of age on fecundity and outcome of pregnancy. BMJ, 302(6789), 1361-1365.

Villa, P. \& Bettio, F. (1998). A Mediterranean perspective on the break-down of the relationship between participation and fertility. Cambridge Journal of Economics, 22(2), 137171.

Walsh, R.A. (1994). Effects of maternal smoking on adverse pregnancy outcomes: examination of the criteria of causation. Human Biology, 66(6), 1059-1092.

Wilde, E.T., Batchelder, L., \& Ellwood, D.T. (2010). The impact of childbearing on wages of women of differing skill levels. NBER Working Paper, 16582. Boston (MA): NBER. 


\section{TABLES}

Table 1. Sample selection criteria

\begin{tabular}{ll}
\hline & N. obs. \\
\hline Original sample size & 32,459 \\
(a) Not the first parity & 16,243 \\
(b) Had other children & 1,130 \\
(c) Current pregnancy & 1,386 \\
(d) Twin-birth & 440 \\
(e) Out of the labor market before birth & 3,608 \\
(f) Age at first birth $>34$ & 1,634 \\
(g) Missing covariates & 209 \\
\hline Final sample & 7,809 \\
\hline
\end{tabular}

Note. The table shows the original sample size and the exclusion criteria used to obtain the final sample. 
Table 2. Sample descriptive statistics

\begin{tabular}{|c|c|c|}
\hline Variable & Mean & S.D. \\
\hline \multicolumn{3}{|l|}{ Mother's age at first birth } \\
\hline less than 25 & 0.196 & 0.397 \\
\hline $25-27$ & 0.224 & 0.417 \\
\hline $28-29$ & 0.207 & 0.405 \\
\hline $30-31$ & 0.172 & 0.377 \\
\hline $32-24$ & 0.201 & 0.401 \\
\hline Mother's labor force participation (LFP) & 0.819 & 0.385 \\
\hline weekly working hours & 24.229 & 16.404 \\
\hline \multicolumn{3}{|l|}{ Woman's education (medium) } \\
\hline ISCED 0-2 & 0.240 & 0.427 \\
\hline ISCED 5-6 & 0.168 & 0.374 \\
\hline \multicolumn{3}{|l|}{ Area of residence (Center) } \\
\hline North-West & 0.212 & 0.409 \\
\hline North-East & 0.249 & 0.433 \\
\hline South and Islands & 0.304 & 0.460 \\
\hline No. of desired children & 1.944 & 0.635 \\
\hline Child age (months) & 21.777 & 2.198 \\
\hline \multicolumn{3}{|l|}{ Wave (2003) } \\
\hline 2005 & 0.488 & 0.500 \\
\hline \multicolumn{3}{|l|}{ Child's birth weight } \\
\hline Low birth weight $(<2,500$ grams $)$ & 0.054 & 0.227 \\
\hline Missing birth weight & 0.000 & 0.016 \\
\hline \multicolumn{3}{|l|}{ Partner's education (ISCED 3-4) } \\
\hline ISCED 0-2 & 0.378 & 0.485 \\
\hline ISCED 5-6 & 0.118 & 0.322 \\
\hline \multicolumn{3}{|l|}{ Partner's qualification (self-employed) } \\
\hline White-collar worker & 0.323 & 0.468 \\
\hline Blue-collar worker & 0.347 & 0.476 \\
\hline \multicolumn{3}{|l|}{ Partner's sector of activity (private sector) } \\
\hline Public sector & 0.165 & 0.371 \\
\hline
\end{tabular}

Note. The sample includes 7,809 observations, as selected in Table 1. S.D. stands for Standard Deviation. 
Table 3. Women's characteristics by fertility shock's status

\begin{tabular}{|c|c|c|c|}
\hline variable & $\begin{array}{l}\text { subject to } \\
\text { fertility shock } \\
\text { (A) } \\
\text { mean }\end{array}$ & $\begin{array}{l}\text { not subject to } \\
\text { fertility shock } \\
\text { (B) } \\
\text { mean }\end{array}$ & $\begin{array}{l}\text { Difference } \\
\text { in means } \\
\text { (A)-(B) }\end{array}$ \\
\hline \multicolumn{4}{|l|}{ Woman's education (ISCED 3-4) } \\
\hline ISCED 0-2 & 0.238 & 0.261 & $-0.023[0.146]$ \\
\hline ISCED 5-6 & 0.170 & 0.180 & $-0.010[0.445]$ \\
\hline \multicolumn{4}{|l|}{ Woman's residence (Center) } \\
\hline North West & 0.21 & 0.213 & $-0.003[0.854]$ \\
\hline North East & 0.245 & 0.264 & $-0.019[0.235]$ \\
\hline South-Islands & 0.31 & 0.289 & $0.022[0.203]$ \\
\hline N. of desired children & 1.946 & 1.919 & $0.027[0.251]$ \\
\hline \multicolumn{4}{|l|}{ Partner's education (ISCED 3-4) } \\
\hline ISCED $0-2$ & 0.377 & 0.374 & $0.003[0.869]$ \\
\hline ISCED 5-6 & 0.120 & 0.112 & $0.008[0.481]$ \\
\hline \multicolumn{4}{|l|}{ Partner's qualification (self-employed) } \\
\hline White-collar worker & 0.321 & 0.341 & $-0.020[0.252]$ \\
\hline Blue-collar worker & 0.347 & 0.333 & $0.014[0.418]$ \\
\hline \multicolumn{4}{|l|}{$\begin{array}{l}\text { Partner's sector of activity (private } \\
\text { sector) }\end{array}$} \\
\hline Public sector & 0.167 & 0.172 & $-0.005[0.679]$ \\
\hline
\end{tabular}

Note. $p$-values in brackets. 
Table 4. Effect of age at first birth on new mother's LFP and working hours

\begin{tabular}{|c|c|c|c|c|c|c|}
\hline \multirow[b]{3}{*}{ variable } & \multirow{2}{*}{\multicolumn{2}{|c|}{$\begin{array}{c}\text { first-stage } \\
\text { Age at first birth }\end{array}$}} & \multicolumn{4}{|c|}{ second stages } \\
\hline & & & \multicolumn{2}{|c|}{ LFP } & \multicolumn{2}{|c|}{ working hours } \\
\hline & coef. & s.e. & coef. & s.e. & coef. & s.e. \\
\hline No. abortions and stillbirths & $0.766 * * *$ & $(0.104)$ & - & - & - & - \\
\hline Predicted age at first birth & - & - & $0.012 * * *$ & $(0.004)$ & $0.535 * * *$ & $(0.141)$ \\
\hline Foreign born (born in Italy) & $-1.507 * * *$ & $(0.306)$ & $-0.156 * * *$ & $(0.074)$ & $-6.904 * * *$ & $(2.169)$ \\
\hline \multicolumn{7}{|l|}{ Education (ISCED 3-4) } \\
\hline ISCED 0-2 & $-1.052 * * *$ & $(0.133)$ & $-0.103 * * *$ & $(0.027)$ & $-3.443 * * *$ & $(0.960)$ \\
\hline ISCED 5-6 & $2.136 * * *$ & $(0.115)$ & $0.060 * * *$ & $(0.022)$ & $1.921 * *$ & $(0.825)$ \\
\hline \multicolumn{7}{|l|}{ Area of residence (Center) } \\
\hline North-West & 0.088 & $(0.147)$ & $0.048 * *$ & $(0.024)$ & $2.486 * * *$ & $(0.929)$ \\
\hline North-East & -0.034 & $(0.138)$ & $0.050 * *$ & $(0.021)$ & $2.501 * * *$ & $(0.884)$ \\
\hline South and Islands & $-0.969 * * *$ & $(0.137)$ & $-0.064 * * *$ & $(0.021)$ & $-4.349 * * *$ & $(0.852)$ \\
\hline N. of desired children & $-0.842 * * *$ & $(0.077)$ & $-0.018^{*}$ & $(0.011)$ & -0.285 & $(0.481)$ \\
\hline \multicolumn{7}{|l|}{ Wave (2003) } \\
\hline 2005 & 0.133 & $(0.100)$ & 0.024 & $(0.025)$ & -0.291 & $(0.863)$ \\
\hline Child age in months & - & - & -0.003 & $(0.005)$ & 0.135 & $(0.176)$ \\
\hline Single (married) & - & - & 0.000 & $(0.021)$ & -0.766 & $(0.831)$ \\
\hline \multicolumn{7}{|l|}{ F-test no. abortions and } \\
\hline N. observations & \multicolumn{2}{|c|}{7,809} & \multicolumn{2}{|c|}{7,809} & \multicolumn{2}{|c|}{7,809} \\
\hline
\end{tabular}

$*, * *, * * *$ statistically significant at the $10 \%, 5 \%$ and $1 \%$ level.

Note. The table shows the results of two-step estimation. In the first stage an interval regression for age at first birth is estimated using Maximum Likelihood. In the second step the predicted values for age at first birth are replaced in a linear regression for labor force participation and weekly working hours. Standard errors in the second step are corrected following Murphy and Topel (1985). $P$-values in brackets, standard errors in parentheses. Observations are weighted to population proportions. 
Table 5. Models including a proxy of maternal health and partner's characteristics

\begin{tabular}{|c|c|c|c|c|c|c|c|c|}
\hline \multirow{3}{*}{ variable } & \multicolumn{4}{|c|}{ Including proxy of mother's health } & \multicolumn{4}{|c|}{ Including partner's characteristics } \\
\hline & \multicolumn{2}{|c|}{ LFP } & \multicolumn{2}{|c|}{ working hours } & \multicolumn{2}{|c|}{ LFP } & \multicolumn{2}{|c|}{ working hours } \\
\hline & coef. & s.e. & coef. & s.e. & coef. & s.e. & coef. & s.e. \\
\hline Predicted age at first birth & $0.012 * * *$ & $(0.004)$ & $0.532 * * *$ & $(0.140)$ & $0.013 * * *$ & $(.004)$ & $0.506^{* * * *}$ & $(0.154)$ \\
\hline Foreign born (born in Italy) & $-0.156^{* *}$ & $(0.073)$ & $-6.848 * * *$ & $(2.162)$ & $-0.157 * *$ & $(0.077)$ & $-6.948 * * *$ & $(2.090)$ \\
\hline \multicolumn{9}{|l|}{ Education (ISCED 3-4) } \\
\hline ISCED 0-2 & $-0.102 * * *$ & $(0.027)$ & $-3.397 * * *$ & $(0.951)$ & $-0.096 * * *$ & $(0.028)$ & $-3.272 * * *$ & $(0.955)$ \\
\hline ISCED 5-6 & $0.060 * * *$ & $(0.022)$ & $1.954 * *$ & $(0.822)$ & $0.048 * *$ & $(0.022)$ & 1.115 & $(0.817)$ \\
\hline \multicolumn{9}{|l|}{ Area of residence (Center) } \\
\hline North-West & $0.049 * *$ & $(0.024)$ & $2.527 * * *$ & $(0.924)$ & $0.047 * *$ & $(0.024)$ & $2.399 * * *$ & $(0.915)$ \\
\hline North-East & $0.049 * *$ & $(0.020)$ & $2.475 * * *$ & $(0.880)$ & $0.049 * *$ & $(0.021)$ & $2.461 * * *$ & $(0.865)$ \\
\hline South and Islands & $-0.064 * * *$ & $(0.021)$ & $-4.330 * * *$ & $(0.846)$ & $-0.063 * * *$ & $(0.022)$ & $-4.243 * * *$ & $(0.844)$ \\
\hline N. of desired children & -0.018 & $(0.011)$ & -0.313 & $(0.480)$ & $-0.018 *$ & $(0.011)$ & -0.327 & $(0.481)$ \\
\hline \multicolumn{9}{|l|}{ Wave (2003) } \\
\hline 2005 & 0.024 & $(0.025)$ & -0.248 & $(0.863)$ & 0.030 & $(0.027)$ & -0.343 & $(0.912)$ \\
\hline Child age (months) & -0.003 & $(0.005)$ & 0.134 & $(0.177)$ & -0.003 & $(0.006)$ & 0.135 & $(0.184)$ \\
\hline
\end{tabular}




\begin{tabular}{|c|c|c|c|c|c|c|c|c|}
\hline Single (married) & 0.001 & $(0.021)$ & -0.749 & $(0.833)$ & 0.000 & $(0.022)$ & -0.497 & $(0.853)$ \\
\hline \multicolumn{9}{|l|}{ Child's birth weight (no low weight) } \\
\hline Low birth weight $(<2,500$ grams $)$ & -0.037 & $(0.029)$ & $-2.190 *$ & $(1.123)$ & - & - & - & - \\
\hline Missing birth weight & $0.176 * * *$ & $(0.014)$ & 11.756 & $(8.839)$ & - & - & - & - \\
\hline Partner's age & \multicolumn{2}{|c|}{ No } & \multicolumn{2}{|c|}{ No } & \multicolumn{2}{|c|}{ Yes } & \multicolumn{2}{|c|}{ Yes } \\
\hline Partner's education & \multicolumn{2}{|c|}{ No } & \multicolumn{2}{|c|}{ No } & \multicolumn{2}{|c|}{ Yes } & \multicolumn{2}{|c|}{ Yes } \\
\hline Partner's job qualification & \multicolumn{2}{|c|}{ No } & \multicolumn{2}{|c|}{ No } & \multicolumn{2}{|c|}{ Yes } & \multicolumn{2}{|c|}{ Yes } \\
\hline Partner's sector of activity & \multicolumn{2}{|c|}{ No } & \multicolumn{2}{|c|}{ No } & \multicolumn{2}{|c|}{ Yes } & \multicolumn{2}{|c|}{ Yes } \\
\hline No. observations & \multicolumn{2}{|c|}{7,809} & \multicolumn{2}{|c|}{7,809} & \multicolumn{2}{|c|}{7,809} & \multicolumn{2}{|c|}{7,809} \\
\hline
\end{tabular}

Note. The table shows the results of two-step estimation. In the first stage an interval regression for age at first birth is estimated using Maximum Likelihood. In the second step the predicted values for age at first birth are replaced in a linear regression for labor force participation and working hours. The results from the first step are the same as in Table 4. Standard errors in the second step are corrected following Murphy and Topel (1985). Standard errors in parentheses. Observations are weighted to population proportions. 
Table 6. Effect of age at first birth on changes in the job

\begin{tabular}{|c|c|c|c|}
\hline Dependent variable & $\begin{array}{l}\text { coef. of age } \\
\text { at } 1^{\text {st }} \text { birth }\end{array}$ & s.e. & N. obs. \\
\hline \multicolumn{4}{|l|}{ Worsening of job conditions after childbirth } \\
\hline yes, less interesting job tasks & 0.006 & $(0.0136)$ & 4,807 \\
\hline yes, less responsibilities & 0.0062 & $(0.0104)$ & 4,807 \\
\hline yes, less career opportunities & 0.0053 & $(0.0067)$ & 4,807 \\
\hline yes, less training & 0.0019 & $(0.0014)$ & 4,805 \\
\hline yes, lower wage & 0.0010 & $(0.0023)$ & 4,804 \\
\hline yes, lower "job attachment" & 0.0095 & $(0.0129)$ & 4,807 \\
\hline yes, pressures by employer and colleagues & 0.0022 & $(0.0028)$ & 4,804 \\
\hline $\begin{array}{l}\text { Working for the same employer before and } \\
\text { after childbirth }\end{array}$ & 0.022 & $(0.005)$ & 6,482 \\
\hline
\end{tabular}

Note. The estimation samples include only mothers who are working for the same employer before and after first birth. Each row represents a regression using a different dependent variable. The dependent variable is an indicator which takes the value one if the mother answered positively and zero otherwise. Sample sizes differ in each row as we dropped mothers who did not answer to the specific question (three observations at most). The table shows the second step of the estimation. In the first step an interval regression for age at first birth is estimated using Maximum Likelihood. In the second step the predicted values for age at first birth are replaced in a linear regression for the satisfaction concerning some job's aspects. Standard errors in the second step are corrected following Murphy and Topel (1985). Standard errors in parentheses. Observations are weighted to population proportions. 